\title{
Análise de DORT na instalação de forros térmicos através da Análise Ergonômica do Trabalho
}

\author{
Lizandra Garcia Lupi Vergara (UTESC) lizandra@eps.ufsc.br \\ Lúcia Lunelli (UTESC) lucialunelli@ig.com.br \\ Wagner Arantes (UTESC) wagnerarantes@terra.com.br
}

\begin{abstract}
Resumo
Os trabalhadores especializados em instalação de forros térmicos sofrem constantes dores principalmente na região do pescoço e costas durante a execução de suas atividades. Considerando a fadiga muscular oriunda de problemas posturais e os freqüentes acidentes ocorridos com profissionais desta área, utilizou-se a metodologia de Análise Ergonômica do Trabalho para a realização da presente pesquisa, desenvolvida no setor de estamparia de uma indústria têxtil em Jaraguá do Sul-SC. Para a análise das atividades destes trabalhadores, foram consideradas questões relacionadas à sobrecarga física, força aplicada com as mãos, posturas assumidas, organização do trabalho e ferramentas utilizadas, na avaliação simplificada - aplicando o modelo de Check-list de Couto - do fator biomecânico no risco para distúrbios músculo-esqueléticos de membros superiores relacionados ao trabalho. Os resultados do check-list demonstraram que os trabalhadores analisados apresentaram um fator biomecânico muito significativo, com grande risco de obtenção de distúrbios osteomusculares relacionados com o trabalho (DORT). Com o objetivo de garantir melhores condições de trabalho, saúde e segurança dos profissionais de instalação de forros térmicos, foram apresentadas propostas de redesign de equipamentos visando a otimização da atividade, assim como sugeridas melhorias relacionadas à organização do trabalho e prevenção dos distúrbios de membros superiores, baseando-se em princípios ergonomicos.

Palavras chave: Ergonomia, DORT, Segurança
\end{abstract}

\section{Introdução}

A ergonomia tem como finalidade a melhoria e conservação da saúde dos trabalhadores assim como a concepção e garantia de funcionamento satisfatórios do sistema técnico, tanto sob o ponto de vista da produção como da segurança.

Os trabalhadores normalmente classificam os efeitos negativos do trabalho como "fadiga". Segundo Wisner (1997), em função da pouca precisão da expressão fadiga, muitos pesquisadores a substituíram por "carga de trabalho", sendo que no domínio da carga física, existe uma ampla literatura que descreve fatos experimentais relacionados com a complexidade da situação de trabalho, como é o caso da presente pesquisa.

Os efeitos da carga de trabalho sobre os trabalhadores são inúmeros. Conforme Pacheco (2002), para as posturas que exigem torções de tronco, o efeito é o tensionamento dos discos existentes entre as vértebras, a carga assimétrica que exigem das articulações e músculos existentes nos dois lados da coluna, e ainda as posturas prolongadas e movimentos repetitivos por tempo prolongado, que podem causar lesões localizadas, resultando em fadiga muscular.

O corpo humano, segundo Vieira (2000), gasta níveis diferentes de energia dependendo da postura que deve ser assumida. Sendo assim, deve-se considerar a possibilidade de alterações nas posições de trabalho, visto que os dados antropométricos variam de indivíduo para indivíduo. Mas independente da tarefa a ser realizada, deve-se ainda considerar o arranjo do 
ambiente, obstáculos, liberdade de movimentos, altura em que o trabalho é realizado, tempo, intensidade de força, distância, extensão e precisão dos movimentos.

O estudo de caso analisado - instalação de forros térmicos, corresponde a um trabalho de carga muscular estática, levando em consideração que a atividade é realizada acima do nível da cabeça sendo que, conforme define Vieira (2000), quando o músculo atinge $15 \%$ da força muscular máxima o fluxo sangüíneo é reduzido, limitando a duração do trabalho e levando à fadiga muscular até possíveis danos ao conjunto de músculos envolvidos.

Os tipos mais comuns de esforços estáticos dos membros superiores, descritos por Couto (2002) são:

- Braços suspensos, sem apoio;

- Antebraços suspensos, sem apoio;

- Usar a mão como morsa;

- Esforço estático do pescoço para sustentar a cabeça em posição forçada.

Considera-se com posturas forçadas dos membros superiores: braços e antebraços fletidos durante um tempo significativo, os membros superiores elevados como um todo e sem apoio, a cabeça excessivamente fletida ou extendidos, entre outros.

Para o desenvolvimento da presente pesquisa, nos concentraremos na análise dos distúrbios músculo-esqueléticos de membros superiores, por constituírem-se atualmente no principal problema de natureza ergonômica a nível mundial.

São considerados como principais distúrbios músculo-esqueléticos de membros superiores relacionados ao trabalho: a fadiga muscular, os desarranjos biomecânicos inespecíficos, a tendinite e outras inflamações agudas concentradas nas mãos e punhos, antebraços e cotovelos, ombros ou pescoço.

A classificação para estes tipos de distúrbios é feita através da sigla DORT, que significa Distúrbios Osteomusculares Relacionados com o Trabalho. Para Couto (2002), o termo DFS (Distúrbio por Sobrecarga Funcional) está relacionado a uma sobrecarga funcional das estruturas frágeis dos membros superiores, sem o devido tempo de recuperação de sua integridade, podendo acometer qualquer profissional cuja atividade envolva o uso intensivo das mãos enquanto ferramenta de trabalho, o que inclui a atividade de instalação de forros térmicos, principalmente pela utilização e manutenção dos braços por longos períodos acima do nível da cabeça.

\section{Estudo de Caso}

A presente pesquisa utilizou como ferramenta de análise a metodologia de Análise Ergonômica do Trabalho (AET). Para tanto, foram feitas observações da atividade de instalação de forros térmicos de uma empresa especializada, em um local de instalação - o setor de estamparia de uma indústria têxtil localizada em Jaraguá do Sul-SC, assim como aplicadas entrevistas com os trabalhadores para delimitação dos problemas ergonômicos, tais como: posturais, informacionais, interacionais, deslocacionais, operacionais, espaciais, físicoambientais, conforme classificação de Moraes e Frisoni (2001).

Durante o processo de observação constatou-se que exigências físicas são constantes e posturas inadequadas são adotadas para poder desempenhar a atividade em questão, prejudicando todo o sistema muscular. Com estas exigências de forças constantes para a utilização dos equipamentos, aumenta o desgaste físico e em alguns casos ocorrem desajustes no sistema psicossocial, deixando os trabalhadores nervosos e sonolentos, sem vontade de trabalhar. 
A demanda especificada pelos trabalhadores surgiu a partir de reclamações de dores musculares na região do pescoço, dores nas costas, freqüentes quedas e fadiga muscular. É importante destacar que os problemas oriundos da falta, ausência ou negligência de equipamentos e condições organizacionais na realização da atividade também foram de grande importância para a delimitação do problema.

Com a demanda especificada, efetuou-se a análise da tarefa e das atividades para que fosse possível estabelecer um diagnóstico, seguido das recomendações ergonômicas consideradas prioritárias para a atividade de instalação de forros térmicos do setor de estamparia da indústria têxtil analisada.

\section{Análise da Tarefa}

A análise da tarefa envolve uma coleta de informações de como a atividade deverá ser desempenhada. Para Moraes e Mont'alvão (1998), trata-se de detalhes específicos entre o pessoal e os componentes do equipamento de um sistema particular. A seguir são descritos, de forma sucinta, os procedimentos necessários para a instalação de forros térmicos estabelecidos pela empresa especializada em estudo:

- Selecionar todo o material e equipamentos que serão utilizados na obra;

- Transportar o material e equipamentos até o local da instalação;

- Montar o andaime;

- Fixar as ripas e vigas;

- Esticar e fixar o forro;

- Deslocar o andaime para continuar a colocação;

- Verificar a qualidade da colocação do forro;

- Respeitar prazos, acompanhando o cronograma.

Em média são instalados $70 \mathrm{~m}^{2}$ por dia de forros térmicos em 3 funcionários. O cronograma é feito junto ao cliente, tendo como análise suas necessidades e disponibilidades, considerando que como medida de segurança para a instalação do forro térmico é fundamental:

- Fazer o isolamento de 2 metros da área;

- Remover ou isolar a rede elétrica;

- Remover maquinários, se possível;

- Orientar transeuntes a respeito dos riscos de ocorrência de incidentes ou acidentes, evitando interferências no andamento da obra.

\section{Análise das Atividades}

Para analisar as atividades dos trabalhadores em estudo, foi acompanhada uma instalação de forro térmico, conforme ilustram as figuras de 1 à 4 , no setor de estamparia de uma indústria têxtil, observando e cronometrado os procedimentos necessários para a colocação do forro térmico. A execução das atividades foi realizada por três funcionários, cuja seqüência de ações é descrita a seguir.

Após descarregar o material a ser utilizado (20 min.), monta-se o andaime a uma altura de 4 metros no local da instalação (30 min.). Todos os equipamentos e ferramentas (alicate, martelo, estilete, grampeador para madeira, arame e fita isolante térmica) devem então ser levados até a plataforma do andaime (10 min.) antes de se iniciar a instalação. 
Com o uso de um alicate e arame, as ripas de madeira são fixadas nas vigas da estrutura (5 min. cada ripa). Usando um grampeador, prende-se uma das extremidades do forro térmico nas ripas de madeira já instaladas $(2 \mathrm{~min}$.), e em seguida desenrola-se o forro térmico até a próxima ripa de madeira, cortando-o com um estilete e grampeando-o (4 min.). Ainda para concluir a atividade é feita uma verificação da colocação do forro térmico (10 min).
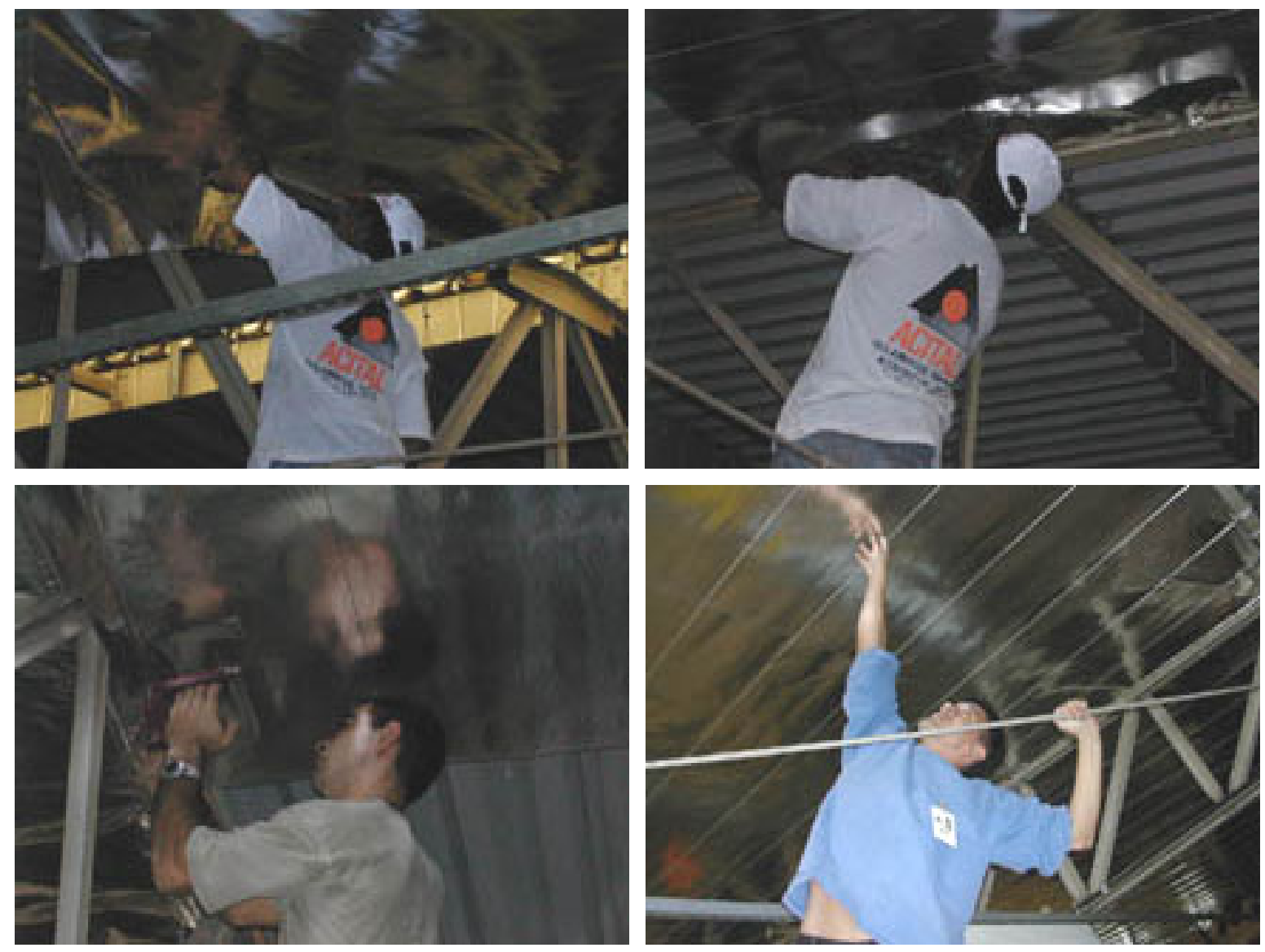

Figuras 1, 2, 3 e 4 - Procedimento de instalação e verificação da colocação do forro térmico.

\section{Diagnóstico}

A partir da análise das atividades, foram diagnosticados problemas considerados prejudiciais à saúde dos trabalhadores, já que a situação de trabalho não atende aos princípios ergonômicos, que visam a redução de esforços físicos e ocorrência de lesões nos trabalhadores, conforme ilustrado pelas figuras de 1 à 4 , as quais retratam a posição inclinada do pescoço, tronco curvado e braços suspensos dos trabalhadores durante a execução do trabalho.

Em relação às posturas assumidas pelos trabalhadores, a sobrecarga muscular dos membros superiores promove distúrbios osteomusculares que são ainda reforçados pela ausência dos equipamentos de proteção e deficiência na estrutura do andaime. A seguir são apresentados alguns problemas identificados, relativos à segurança, equipamentos e condições organizacionais:

- O andaime não possui trava-rodas;

- Não há uso de travas transversais para sustentar o andaime;

- Os trabalhadores não usam cinto de segurança e nenhum outro tipo de equipamento de proteção individual (EPIs); 
- Para deslocar o andaime de lugar, os trabalhadores não descem do mesmo;

- Não há equipamento de transporte do material até o teto, sendo levado pelos próprios trabalhadores;

- Os trabalhadores sobem à plataforma pelo andaime, e não pela escada, sofrendo riscos de queda;

- Não é respeitado o limite de 2 metros de distância para a área de segurança;

- O ambiente é muito quente, empoeirado e com teias de aranha;

- Existem cabos elétricos que deveriam ser removidos ou desviados durante a instalação.

O quadro abaixo apresenta a classificação dos problemas ergonômicos com as devidas sugestões de melhoria da situação de trabalho analisada - a atividade de instalação de forros térmicos, conforme modelo estabelecido por Moraes e Mont'alvão (1998):

\begin{tabular}{|c|c|c|c|c|}
\hline $\begin{array}{l}\text { Classe do } \\
\text { problema }\end{array}$ & Problemas & $\begin{array}{c}\text { Constrangimentos da } \\
\text { tarefa }\end{array}$ & Custos humanos & $\begin{array}{c}\text { Sugestões preliminares } \\
\text { de melhoria }\end{array}$ \\
\hline \multirow[t]{2}{*}{ Interfaciais } & $\begin{array}{l}\text { Rotação do } \\
\text { pescoço, constante } \\
\text { flexão da coluna }\end{array}$ & $\begin{array}{l}\text { Difícil acesso e } \\
\text { adaptação ao local de } \\
\text { instalação (teto) }\end{array}$ & $\begin{array}{l}\text { Dores musculares } \\
\text { e problemas nas } \\
\text { costas, ombros e } \\
\text { pescoço }\end{array}$ & $\begin{array}{l}\text { Promover adaptações na } \\
\text { altura da plataforma do } \\
\text { andaime }\end{array}$ \\
\hline & \begin{tabular}{|l|} 
Braços acima do \\
nível da cabeça por \\
tempo prolongado
\end{tabular} & $\begin{array}{l}\text { Distância estabelecida } \\
\text { entre o teto e o } \\
\text { trabalhador }\end{array}$ & $\begin{array}{l}\text { Sobrecarga } \\
\text { funcional }\end{array}$ & $\begin{array}{l}\text { Utilizar suporte de apoio } \\
\text { aos braços e cabos } \\
\text { adaptáveis às ferramentas }\end{array}$ \\
\hline \multirow[t]{2}{*}{ Movimentacionais } & $\begin{array}{l}\text { Não existe } \\
\text { equipamento para } \\
\text { subida do material }\end{array}$ & $\begin{array}{l}\text { Subir e descer do } \\
\text { andaime carregando o } \\
\text { material nas costas }\end{array}$ & $\begin{array}{l}\text { Sobrecarga } \\
\text { muscular }\end{array}$ & $\begin{array}{l}\text { Acoplar um sistema de } \\
\text { roldanas à plataforma do } \\
\text { andaime para subida de } \\
\text { equipamentos }\end{array}$ \\
\hline & $\begin{array}{l}\text { Subir pelo andaime } \\
\text { até a plataforma }\end{array}$ & $\begin{array}{l}\text { Grandes alturas com } \\
\text { degraus de aprox. } 1 \\
\text { metro de distância }\end{array}$ & Quedas & $\begin{array}{l}\text { Adaptar escada de subida } \\
\text { para os trabalhadores e } \\
\text { utilizar cinto de segurança }\end{array}$ \\
\hline Psicossociais & $\begin{array}{l}\text { Conflitos entre os } \\
\text { trabalhadores }\end{array}$ & $\begin{array}{l}\text { Dificuldades de } \\
\text { comunicação }\end{array}$ & $\begin{array}{l}\text { Sistema } \\
\text { emocional } \\
\text { abalado }\end{array}$ & $\begin{array}{l}\text { Providenciar sistema de } \\
\text { comunicação entre os } \\
\text { trabalhadores e pausas de } \\
\text { recuperação }\end{array}$ \\
\hline \multirow[t]{2}{*}{ Acidentários } & \multirow{2}{*}{$\begin{array}{l}\text { Deficiência nos } \\
\text { equipamentos e } \\
\text { segurança }\end{array}$} & $\begin{array}{l}\text { Irregularidades no } \\
\text { andaime }\end{array}$ & $\begin{array}{l}\text { Desgaste físico e } \\
\text { fadiga muscular }\end{array}$ & $\begin{array}{l}\text { Adaptar o andaime à } \\
\text { atividade }\end{array}$ \\
\hline & & $\begin{array}{l}\text { Quedas dos } \\
\text { trabalhadores }\end{array}$ & $\begin{array}{l}\text { Acidentes } \\
\text { pessoais }\end{array}$ & $\begin{array}{l}\text { Fazer uso de EPIs, trava- } \\
\text { rodas, trava transversal do } \\
\text { andaime e escada }\end{array}$ \\
\hline Operacionais & Ritmo intenso & $\begin{array}{l}\text { Cumprimento de } \\
\text { prazos }\end{array}$ & $\begin{array}{l}\text { Desgaste físico e } \\
\text { fadiga muscular }\end{array}$ & $\begin{array}{l}\text { Rodízio de tarefas e } \\
\text { pausas de recuperação }\end{array}$ \\
\hline Espaciais & $\begin{array}{l}\text { Isolamento } \\
\text { inexistente }\end{array}$ & $\begin{array}{l}\text { Quedas de ferramentas } \\
\text { e materiais de } \\
\text { instalação }\end{array}$ & $\begin{array}{l}\text { Eventuais } \\
\text { incidentes ou } \\
\text { acidentes }\end{array}$ & $\begin{array}{l}\text { Cercar a área prescrita na } \\
\text { tarefa - de } 2 \text { metros } \\
\text { quadrados }\end{array}$ \\
\hline
\end{tabular}

Quadro 1 - Caracterização dos problemas ergonômicos e sugestões de melhoria da situação de trabalho.

Como forma de avaliar os problemas ergonômicos identificados na situação de trabalho em estudo, foi aplicado entre os trabalhadores o modelo de check-list de Couto (2002), o qual tem como objetivo verificar, de forma simplificada, o fator biomecânico no risco de obtenção de distúrbios músculo-esqueléticos nos membros superiores relacionados ao trabalho, no caso à atividade de instalação de forros térmicos do setor de estamparia de uma indústria têxtil. 
Os resultados do check-list demonstraram que estes trabalhadores apresentaram um fator biomecânico muito significativo com um total de apenas 7 pontos - classificação mais grave, de acordo com o critério de avaliação do Check-list de Couto. Isto significa que a atividade de instalação de forros térmicos desenvolvida por estes profissionais apresentam vários problemas considerados ergonômicos, relacionados diretamente com a sobrecarga física, a força aplicada com as mãos, as posturas assumidas, a organização do trabalho e ferramentas utilizadas, correndo um grande risco de obtenção de distúrbios músculo-esqueléticos nos membros superiores relacionados ao trabalho.

\section{Recomendações Ergonômicas}

As recomendações ergonômicas têm por objetivo propor melhorias aos problemas identificados, permitindo ao trabalhador executar suas atividades com o mínimo de exigências físicas, evitando a sobrecarga muscular.

Baseando-se em princípios ergonômicos, propõe-se alguns procedimentos relativos à segurança e saúde dos trabalhadores, no que diz respeito à prevenção aos distúrbios de membros superiores relacionados ao trabalho, tais como:

a. Redução dos esforços manuais dos trabalhadores durante a execução da atividade. Para tanto se sugere o redesign do andaime, conforme demonstram as figuras 5, 6 e 7, disponibilizando:

- Adaptações para mudança na altura da plataforma, evitando a sobrecarga muscular dos trabalhadores (fig. 5);

- Adaptação de uma escada de encaixe no andaime para a subida dos trabalhadores (fig. 6);

- Utilização de um sistema de roldanas acoplável à plataforma do andaime para subida de equipamentos e ferramentas de trabalho (fig. 7);

- Utilização de cinto de segurança e demais equipamentos de proteção individual (EPIs) necessários à execução da atividade em questão;

- Utilização de trava-rodas e travas transversais para sustentação do andaime para evitar deslocamentos desnecessários e riscos de quedas. Ainda para segurança, deve-se isolar a área em 2 metros de distância do local de instalação do andaime.

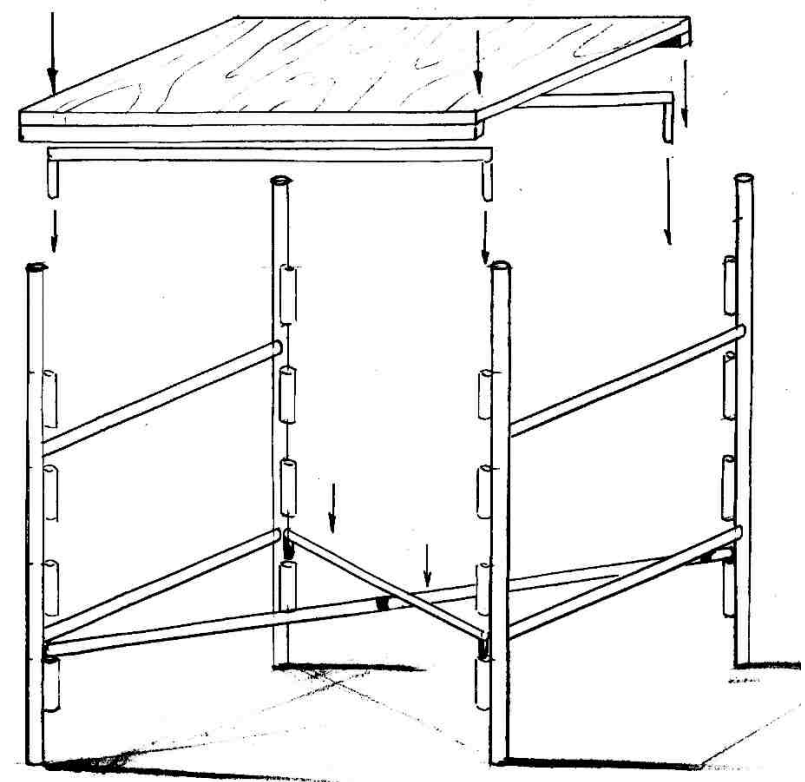

Figura.5 - Andaime com estrutura adaptável à diversas alturas, finalizando com a fixação da plataforma. 


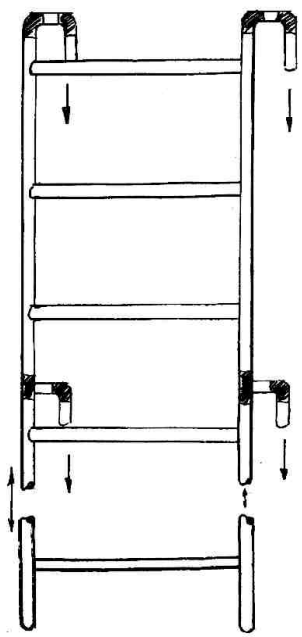

Figura.6 - Escada acoplável à estrutura do andaime para subida e descida dos trabalhadores.

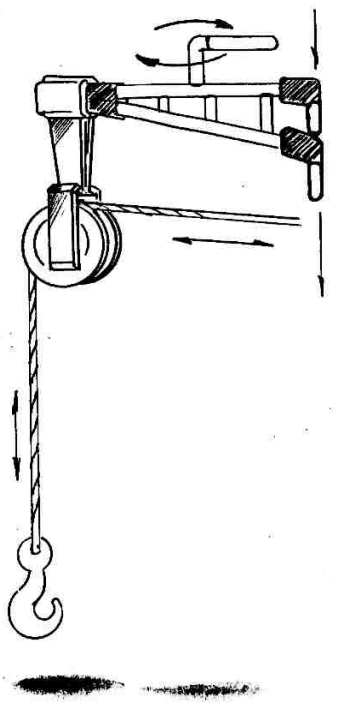

Figura. 7 - Sistema de roldanas para subida e descida de equipamentos.

b. Adaptar a postura do trabalhador ao posto de trabalho. Para tanto, propõe-se:

- Alternar a altura do andaime de forma a evitar a inclinação excessiva da cabeça do trabalhador;

- Colocar um suporte de apoio aos braços, reduzindo o esforço estático da musculatura do ombro;

- Utilizar cabos adaptáveis às ferramentas utilizadas pelos trabalhadores, para extensão e redução da distância ao teto.

c. Em relação às questões organizacionais, sugere-se:

- Permitir pausas de recuperação, e rodízio de tarefas entre os trabalhadores;

- Realizar treinamento prévio de pessoal para o conhecimento da tarefa prescrita;

- Conscientizar os trabalhadores a respeito dos princípios ergonômicos e riscos ocupacionais através de cursos específicos.

\section{Conclusão}

A negligência aos padrões de qualidade ocupacional e a exposição a situações causadoras de riscos de incidentes ou acidentes, tendem a estimular a ocorrência de enfermidades ao trabalhador. O estudo realizado na atividade de instalação de forro térmico no setor de estamparia de uma indústria têxtil, apresentou problemas relacionados aos distúrbios osteomusculares relacionados com o trabalho (DORT), oriundos de queixas de dores no pescoço e costas dos trabalhadores, assim como fadiga muscular, os quais foram analisados utilizando a ferramenta metodológica de análise ergonômica do trabalho.

Através da aplicação do Check-list de Couto, pode-se constatar que os trabalhadores apresentaram um fator biomecânico muito significativo ao realizar a atividade analisada, principalmente no que diz respeito à sobrecarga física, força aplicada com as mãos, posturas assumidas, organização do trabalho e ferramentas utilizadas, o que resulta em grande risco de obtenção de distúrbios osteomusculares relacionados com o trabalho. 
Em relação à segurança dos trabalhadores, propõe-se adaptação nos equipamentos utilizados, como a colocação de uma escada acoplada na lateral do andaime, a implantação de um sistema de roldanas para suspensão dos materiais, prevenindo acidentes causados pela queda de equipamentos e pessoal; além da utilização de cabos adaptáveis às ferramentas e suportes de apoio para os braços dos trabalhadores, como forma de amenizar os problemas relacionados à sobrecarga muscular responsáveis pela ocorrência de DORT.

Ainda foram apresentadas propostas de redesign do equipamento - andaime, proporcionando a adequação às necessidades dos trabalhadores e exigências do ambiente e viabilizando a realização da atividade de instalação de forros térmicos, a fim de garantir melhores condições de trabalho, saúde e segurança aos trabalhadores.

\section{Referências}

COUTO, Hudson A. (2002) - Ergonomia aplicada ao trabalho em 18 lições. Belo Horizonte, Ergo Editora Ltda. MORAES, Anamaria; FRIZONI, Bianka C. (2001) - Ergodesign: produtos e processos., Rio de Janeiro, Editora $2 \mathrm{AB}$.

MORAES, Anamaria \& MONT’ALVÃO, Cláudia. (1998) - Ergonomia, conceitos e aplicações. Rio de Janeiro, Editora 2AB.

PACHECO, Waldemar Jr. (2002) - Apostila de Engenharia de Segurança do Trabalho. Curso de Especialização. Florianópolis, UFSC.

VIEIRA, Sebastião I. (2000) - Manual de Saúde e Segurança do Trabalho. Florianópolis, Mestra.

WISNER, A. (1997) - A inteligência do trabalho: textos selecionados de ergonomia. São Paulo, Fundacentro. 